\title{
Human development versus Economic growth: India and South Asia at crossroads
}

\author{
Dr. Sushma Sahai \\ Assistant Professor, Department of Geography, Loreto College, Kolkata, West Bengal, India
}

\begin{abstract}
The era of globalization has been marked by dramatic advances in technology, trade and investmentand an impressive increase in prosperity. Comparatively the gains in Human Development (HD) have been less impressive. Large parts of developing world are being left behind. HD gaps between rich and poor countries, already large are widening. The fruits of globalization have been reaped by a number of countries, but they have not been able to translate their rising prosperity into HD. The Millennium Development Goals (MDGs) which stress on right to education, gender equality, infant mortality and decent standard of living are universal in nature. The progress towards the MDGs will be possible only if the benefits from economic growth are invested in the social sectors. This study aims at scrutinizing the lessons from other nations of South Asia and compares the levels of human development in India.
\end{abstract}

Keywords: Human development, Millennium Development Goals, economic growth, social sectors

\section{Introduction}

The beginning of the twenty-first century was marked by a number of events which illustrated the importance of the challenges of development. Deepening global inequalities have led to poverty and deprivation whereas economic development has gained center stage. This has caused widespread social and environmental strains that threaten to derail developmental efforts and erode living standards.

Human development gaps within countries are as stark as the gaps between countries. These gaps reflect unequal opportunity- people held back because of their gender, group identity, wealth or location. Overcoming the structural forces that create and perpetuate extreme inequality is one of the most efficient routes for overcoming poverty, enhancing the welfare of society and accelerating progress towards the Millennium Development Goals (MDGs).(Human Development Report,2005)

The MDGs themselves are a vital statement of international purpose rooted in commitment to basic human rights. These rights- to education, to gender equality, to survival in childhood and to a decent standard of living-are universal in nature. That is why progress towards the MDGs should be for all people, regardless of their income, their gender and location.

Today, the world has the financial, technological and human resources to make a decisive breakthrough in Human Development (HD).But if the current trends continue; the MDGs will be missed by a wide margin.

Meanwhile, some of the countries most widely cited as examples of globalization "success stories" are finding it harder to convert rising prosperity into human development. Progress in reducing child mortality, one of the basic of HD indicators, is slowing, and the child death gap between rich and poor countries is widening. For all the highly visible achievements, the reach for global scientific advancement falls far short of ending the unnecessary suffering, debilitating diseases and death from preventable illness that blight the lives of the world's poor.(Human Development Report,2005, p.19)

\section{Human Development Index - A Mirror of Development}

Human Development Index (HDI) is a composite indicator. It covers three dimensions of human welfare: income, education and health. Its purpose is not to give a complete picture of HD but to provide a measure that goes beyond income. The HDI is a barometer for changes in human well-being and for comparing progress in different regions.

Over the last decade the HDI has been rising across all countries, though at variable rates. Amid the overall progress, not only have regional disparities widened as seen in Fig 1 but the intra - regional differences in terms of HD have also surfaced. Fig 2 illustrates that the South Asian countries are not witnessing similar levels of human development. 
The relationship between wealth ranking and HDI ranking varies across countries. Bangladesh and China are two of the fastest climbers in the HDI ranking. Since 1990 Bangladesh has risen 14 places in the HDI ranking but just 10 places in the global wealth ranking. What this suggests is that social progress in Bangladesh has outstripped economic advance relative to the performance of other countries. Conversely, China has continued its impressive ascent of HDI ranking, but economic advance has outpaced social advance. The country has climbed 20 places in the HDI ranking and 32 places in wealth ranking. (Human Development Report, 2011)

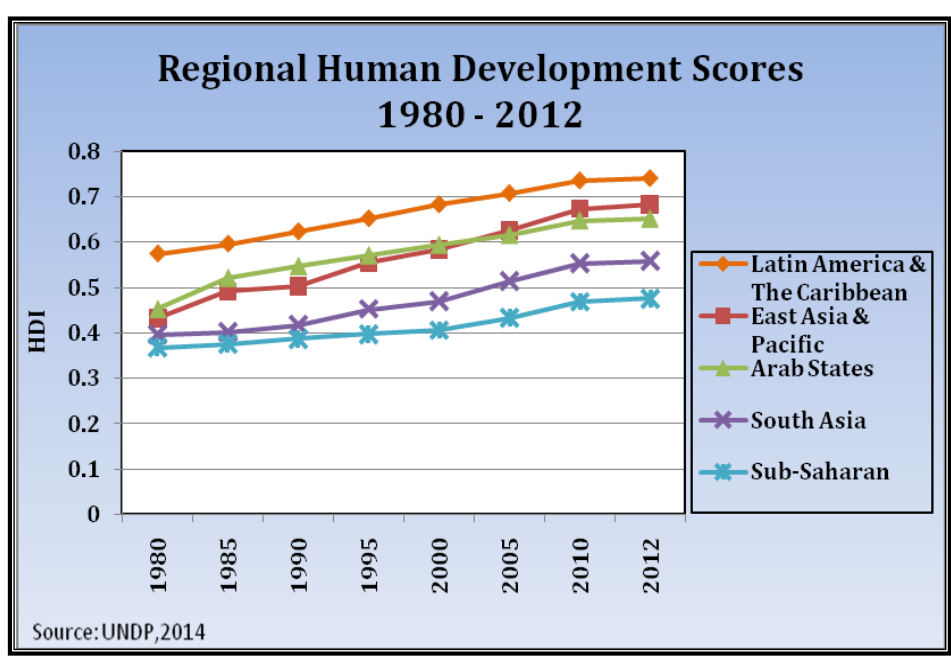

Figure 1

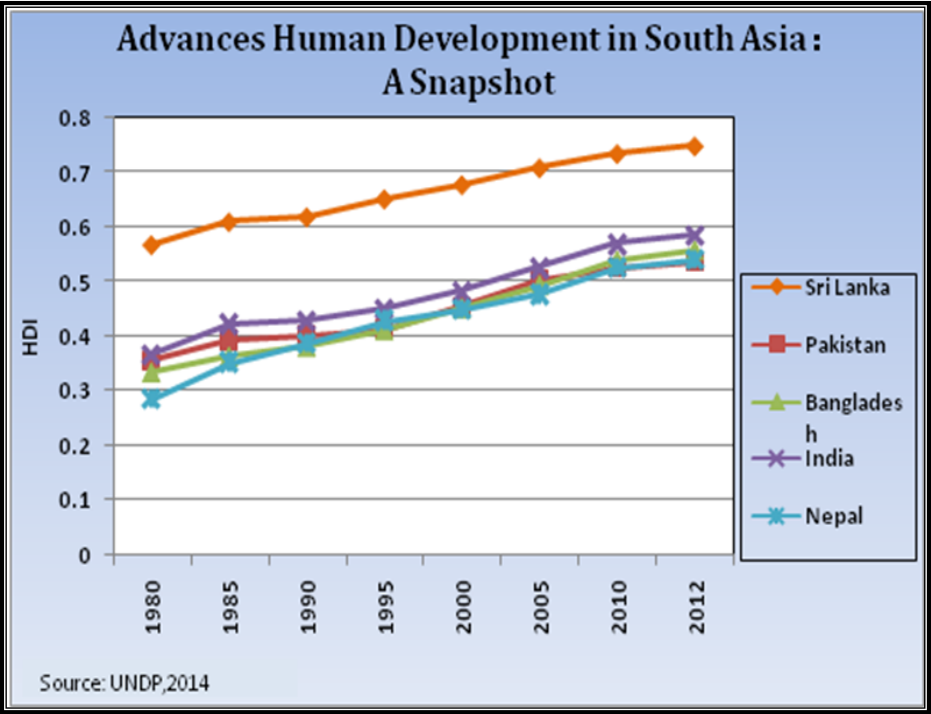

Figure 2
Human Development has been recently advanced as the ultimate objective of human activity in place of economic growth. Human Development has been defined as enlarging people's choices in a way which enables them to lead longer, healthier and fuller lives. (Human Development Report, 2005) There exists a strong connection between economic growth (EG) and HD. On one hand, EG provides the resources to permit sustained developments in HD. On the other hand, improvements in the quality of labour force are an important contributor to EG. HD primarily consists of health and education of its people. One of the primary objective of this paper is to sharpen understanding of the two-way links between HD and EG at both theoretical and empirical levels. This would assist to identify priority areas and formulate policies to achieve progress in HD.

\section{Cycles of Development}

There are two chains, viz., EG to HD and HD to EG which indicate that an economy may be on a mutually reinforcing upward spiral, with high levels of HD leading to high growth which in turn results in promoting HD. Contrary, weak HD would result in decline levels of growth and poor progress towards HD. The strength of the links in the two chains influences the extent of mutual reinforcement between HD and EG, in either direction.

The Chain from HD to EG, indicates that healthier, well nourished and educated individuals contribute productively to EG. Higher levels of HD affect the economy by empowering and enhancing people's capabilities and in turn their productivity and creativity. Health and education the two pillars on which HD rests are the most important determinants of the nature and growth of trade and constitute an important ingredient in a system's capacity to borrow foreign technology effectively.

In agriculture, evidence suggests positive effects on productivity among farmers adopting modern technology, but less impact was seen among those using traditional methods. In Thailand, farmers with four or more years of schooling were three times more likely to adopt fertilizer and other modern inputs than less educated farmers. Similarly, in Nepal, the completion of at least seven years of schooling increased productivity in wheat by over a quarter and in rice by $13 \%$. 
Education is also an important contributor to technological capability and technical change in industry. Statistical analysis of the clothing and engineering industries in Sri Lanka showed that the skill and education levels of workers and entrepreneurs were positively related to the rate of technical change of the firm.

Country performance can therefore be classified into four categories, virtuous, vicious and two types of lop-sidedness, i.e. lop-sided with strong HD/ weak growth (called HD-lopsided); and lop-sided with weak HD/ strong growth (EG-lopsided). In the virtuous cycle case, good HD enhances growth, which in turn promotes $\mathrm{HD}$. In the vicious cycle case, poor performance in HD tends to lead to poor growth performance which in turn depresses HD achievements. The stronger the linkages between the two chains, the more pronounced the cycle of economic growth and HD, either in a positive or negative manner. Where linkages are weak, cases of lopsided development may occur. On the one hand, good economic growth may not bring about good HD, if for e.g. if the social expenditure ratio is low; on the other hand, good HD performance may not generate good EG if there is a dearth of complementary resources because of low investment rates. (Ranis, G.,et al.,2005)

\section{HD - EG Changes Of South Asian Countries Over Three Decades (1970-2000)}

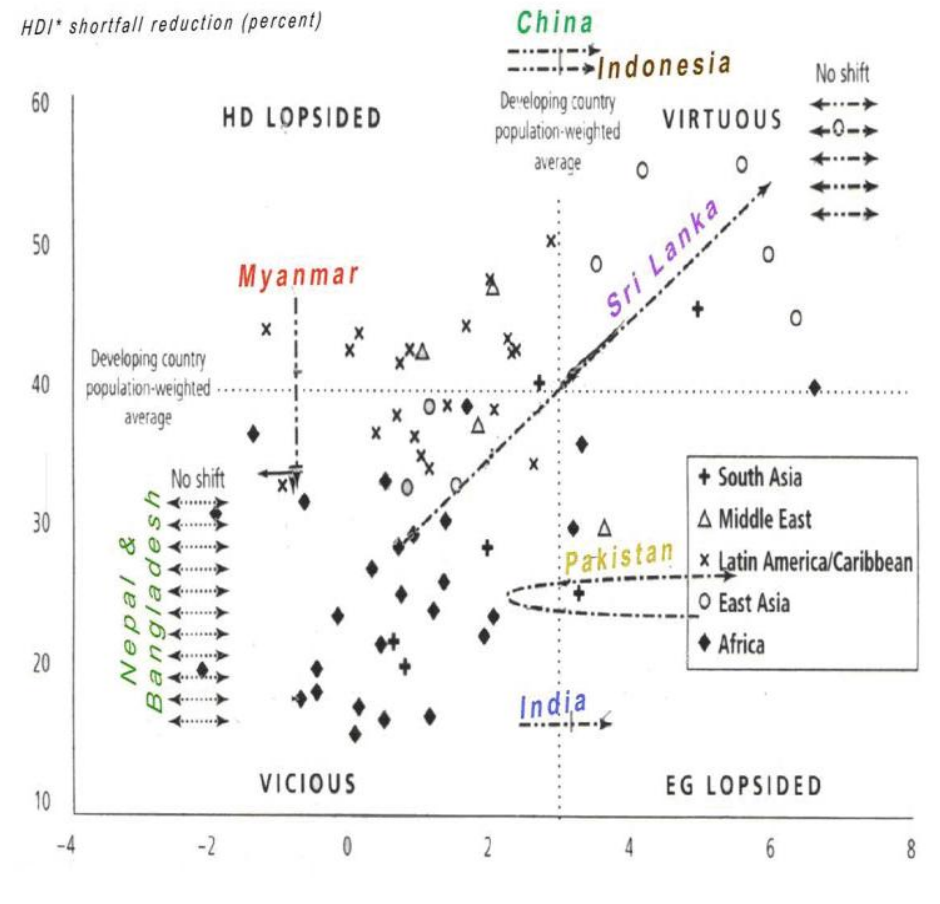

Fig.3 represents the classified selected countries of South Asia. The vertical and horizontal grid lines represent the average performance for the period. As indicated most developing countries fall in either virtuous (NE quadrant) or vicious (SW quadrant). They exhibit low growth rates and debt crisis preventing them from generating the resources necessary for HD.A strong regional pattern emerges, with South and East Asia heavily represented in the virtuous cycle case. Of the 37 countries in the vicious cycle quadrant, 21 are from Sub-Saharan Africa, 9 from Latin America. In the EG lopsided category Pakistan shares the space with Egypt, Mauritius and Lesotho. (Ranis, G.,et al.,2005, p.73)

Figure 3

These categories should not be treated in watertight compartments, as each country with passage of time witnesses a change in EG and may or may not register a subsequent change in HD. For example Sri Lanka is the sole country in South Asia which managed to move from vicious to virtuous category on a sustained basis.

\section{Financing Human Development}

Judicious and timely expenditure should be the priority for all governments, especially in social sectors. Statistics reveal that governments are not allocating substantial funds for the development of educational and health sectors. The GNP of every nation is allocated to the various departments which not only ensures economic growth but simultaneously creates an conducive environment for the welfare and development of its citizens.

The Social allocation ratio which is the percentage of public expenditure earmarked for social services are not satisfactory. Government spending varies on expenditure in social sectors. The social allocation ratio ranges from $13 \%$ in Indonesia to $50 \%$ in Chile and Costa Rica. The state and local governments play a very important role in financing health, nutrition, sanitation and education. In India $85 \%$ of the social spending is received from these sources (Ranis, 2005).Though the social development is an integral part of the growth of any region, statistics revel that expenditure on defence ranks first in South Asia, which in turn diverts the most needed resources away from sectors like health and family welfare.

The Human Expenditure Ratio is lowest in India, Pakistan and Bangladesh, with only 5\% of the GNP spent in social priority areas. Though it is not imperative that a larger share of GNP diverted to social sectors 
would register an increase in the HD, it is no doubt that it remains an important indicator of the objective and policies of the government aiming at human development.

Countries other than Bhutan and Maldives spend less than 2 percent of their Gross National Product (GNP) on public health. India spends 0.7 percent, Pakistan 0.8 percent, Bangladesh 1.2 percent, Nepal 1.2 percent, and Sri Lanka 1.4 percent of their GNP on public health. (World Bank, 2011)

\section{Women and children last}

Child survival is one of the most sensitive indicators of human welfare, the comparative health of nations and the effectiveness of public policy. Against this backdrop child death trends are fast approaching the point that merits declaration of an international health emergency. Globally over 10 million infants die each year before their first birthday. A child less than 5 years old-roughly 1 child died every 3 seconds. An estimated 4 million of these deaths happened in the first month of life, the neonatal period. Almost all child deaths happen in developing countries, while most of the spending to prevent child deaths happens in rich ones. Infant mortality deprives a nation of its potential human capital.

Substantial progress has been made towards achieving the MDG.The number of under five deaths worldwide has declined from 12.6 million in 1990 to 6.6 million in 2012. While that translates into around 17,000 fewer children dying everyday in 2012 than in 1990, it still implies the deaths of nearly 18,000 children under age five everyday in 2012.

Under- five deaths are increasingly concentrated in Sub- Saharan Africa and Southern Asia, while the share in the rest of the world dropped from 32 percent in 1990 to 18 percent in 2012.About half of the under five deaths occur in only five countries: India, Nigeria, Democratic Republic of the Congo, Pakistan and China. India (22 percent) and Nigeria (13 percent) together account for more than a third of all under - five deaths. (UNICEF, 2013).

Rapid growth has been witnessed and the country is on track for the MDG target of halving poverty, but India is widely off track for the child mortality target. Developments in India and China have global implications. India alone accounts for 2.5 million child deaths annually, one in 5 of the world total.

Low income is not a barrier to progress. Vietnam and Bangladesh have both accelerated the pace of child mortality reduction. Indeed, at a lower level of income and a comparable rate of economic growth, Vietnam has now overtaken China on improvement in child mortality. Similarly at a lower level of income and with far lower growth, Bangladesh has overtaken India. These differences matter. Had India matched Bangladesh rate of reduction in child mortality over the past decade, fewer children would have lost their lives.

\section{Infant and Child Mortality}

Reduction in infant and child mortality is likely the most important of the Millennium Development Goals (MDGs), as children are the assets of the nation. In India, approximately, 1.72 million children die every year, before reaching their first birthday, which represents one of the greatest wastes of human potential in the country. The MDG is to reduce ICMR by 2/3rds between 1990-2015. For India this would imply a reduction of the IMR to 27 and of the U5MR to 32 by 2015 (Deolalikar, A.B., 2005).

While India, has managed to reduce its IMR significantly over the last 3 decades, its performance on IMR reduction is pale in comparison to that of many other countries in South Asia. Even within South Asia, Sri Lanka and Bangladesh have managed to reduce their IMRs at a faster rate than India (4.3\% and 3.3\%).Indeed what is surprising is that the level of IM is greater in India than Bangladesh - a country whose per capita GDP is only about half of India's as seen in Fig.4.

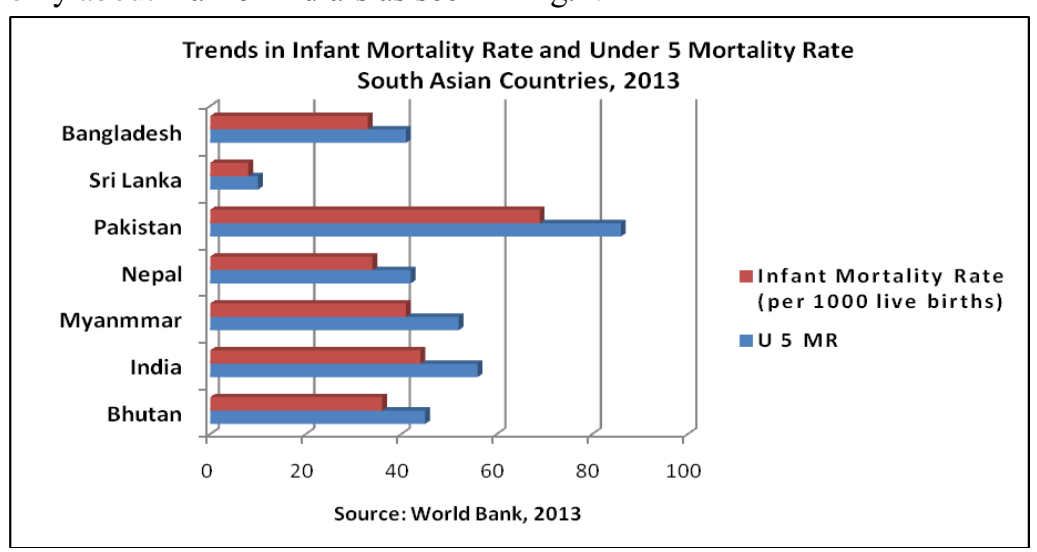

Though survival prospects have improved across all regions, 10.5 million children died before their fifth birthday worldwide in 2004 mostly from preventable causes. In Southern Asia, 3.5 million children die annually before they reach the age of five (India alone counts for 2.3 million under-5 deaths). Southern Asia has made significant progress, but not enough so far to meet the target by 2015 .

Figure 4 
The World Health Organization has established that over half of all child deaths annually are caused by five preventable conditions: diahorrea, acute respiratory infections, measles, malaria, and prenatal conditions. Malnutrition can severely aggravate these conditions; however it is not a leading cause of child mortality itself.

One factor behind the progress in reducing child under-5 mortality in the Asia and Pacific region is that many parts of it have improved general health conditions, especially those which are able to prevent the spread of communicable infectious diseases.

\section{India: Inter-state variations}

There are wide inter-state variations within the country. The IMR ranges from 10 in Goa the smallest state to a high of 56 in Madhya Pradesh one of the largest states of India. The IMR of 10 in the smaller states of Goa and Manipur is comparable to Bulgaria, Russia and Ukraine in terms of IMR, while that of Orissa is comparable to Lesotho, Cameroon and Tanzania.

The data are intriguing, since they go against many widely held perceptions. For instance, the state with the lowest level of IM in 1981-Kerala reduced its IM at the fastest rate (5\% per annum) between 1981-2000. But in Bihar and UP, which had the highest IMR in 1981, were also among the top performers in IMR reduction over the same period. Andhra Pradesh and Karnataka- states that are normally perceived to be good HD performers- had the slowest rate of IMR decline over the last two decades. (Council for Social Development, 2006).

There are several interventions which are pursued simultaneously. It is obvious that, while each of the intervention contributes to the reduction of infant mortality, the ones that are associated with the largest declines are increased maternal care and female schooling. This suggests that a decline in infant mortality is feasible with a package of interventions that include economic growth, increased public spending on nutritional programmes, improved physical infrastructure (electricity, sanitation access, medical assistance at birth and rural roads) and expansion in female schooling. (Deolalikar, A.B., 2005)

The expenditure on public health is not uniform across the states of India. Tamil Nadu with its extensive and relatively better managed public health services and nutrition programmes has clearly emerged as a frontrunner in the reduction of Infant mortality. Thus, Tamil Nadu has halved its IMR in the past decade while Maharashtra, Punjab and Karnataka have shown significant decreases of around $40 \%$.( Sample Registration Scheme Bulletins, 2013\& 2005)

More than 500,000 women die each year in childbirth, most of them in developing countries. What makes maternal mortality such a compelling problem is that it strikes young women who are poor, malnourished, weakened by disease and exposed to multiple pregnancies. The lack of access to trained health care workers and modern medical facilities also adds to the same.

\section{Medical Infrastructure: A Regional disparity}

The growth of hospitals and dispensaries has not been uniform all over India. In some parts of the country, particularly, those that are fortunate to have one or more medical colleges, the advance have been rapid enough. In other parts, especially those with inadequate communication and sparse population, such as Bastar district, Chhattisgarh, the development has lagged behind. Disparities are evident in terms of number of beds/1000 population. The following table 1 reflects the glaring disparities in some states of India.

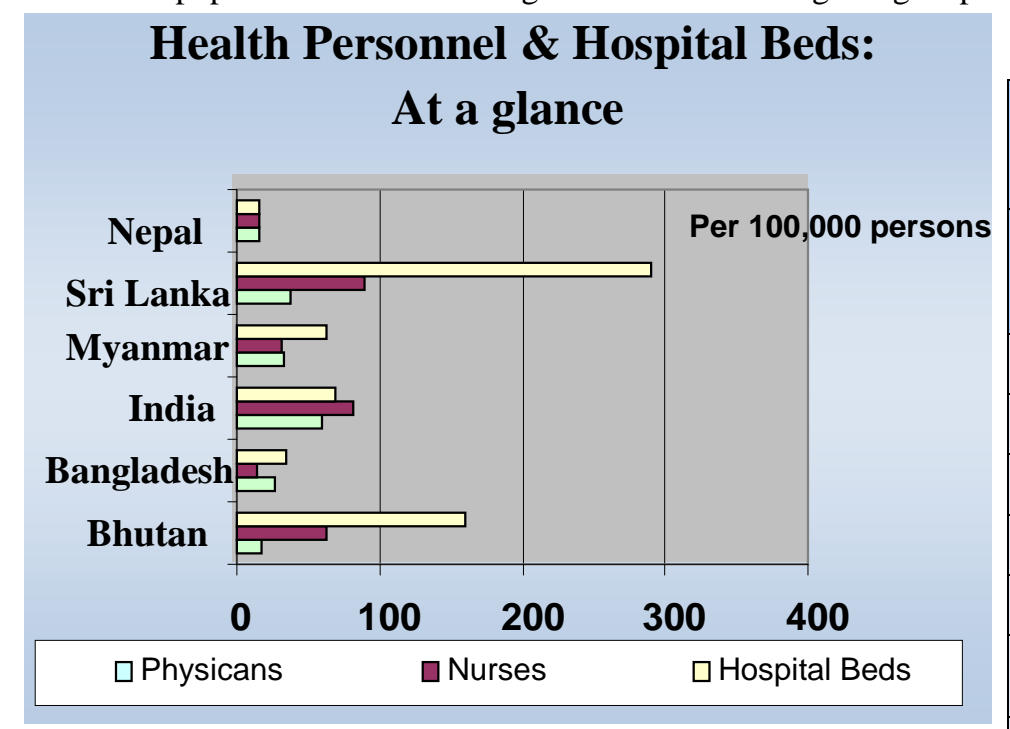

Source: UNDP, 2012

Figure 5

\begin{tabular}{|c|c|}
\hline \multicolumn{2}{|c|}{ Table 1 } \\
Hospital Beds per 1000 population \\
\hline $\begin{array}{c}\text { STATE / UNION } \\
\text { TERRITORY }\end{array}$ & $\begin{array}{c}\text { BEDS/ 1000 } \\
\text { POPULATION }\end{array}$ \\
\hline DELHI & 2.07 \\
\hline WEST BENGAL & 0.87 \\
\hline MADHYA PRADESH & 0.35 \\
\hline BIHAR & 0.51 \\
\hline KERALA & 3.45 \\
\hline ARUNACHAL & 2.10 \\
\hline PRADESH & 4.88 \\
\hline PONDICHERRY & \\
\hline
\end{tabular}


In order to access the development of health services, it was imperative to adopt a quantitative analysis, which would aid in drawing a comprehensive picture of the Medical Intensity of the sub-continent.

The regional variations in the Medical Intensity (MI) have been illustrated in Fig.6 which indicates that it is not homogeneous across the length and breadth of the country. MI varies from a lowest of 0.10 in Lakshadweep to a highest of 4.29 in Maharashtra. This index is an authentic tool to study the variations in not only the number of hospitals, but also in the number of beds, compared state-wise. Majority of the states of India, Jammu and Kashmir and Haryana have the lowest Medical intensities, ranging from 0.01- 1.07.This measure can thus help the both the State and Central Governments to focus on the quantity and quality of medical institutions.

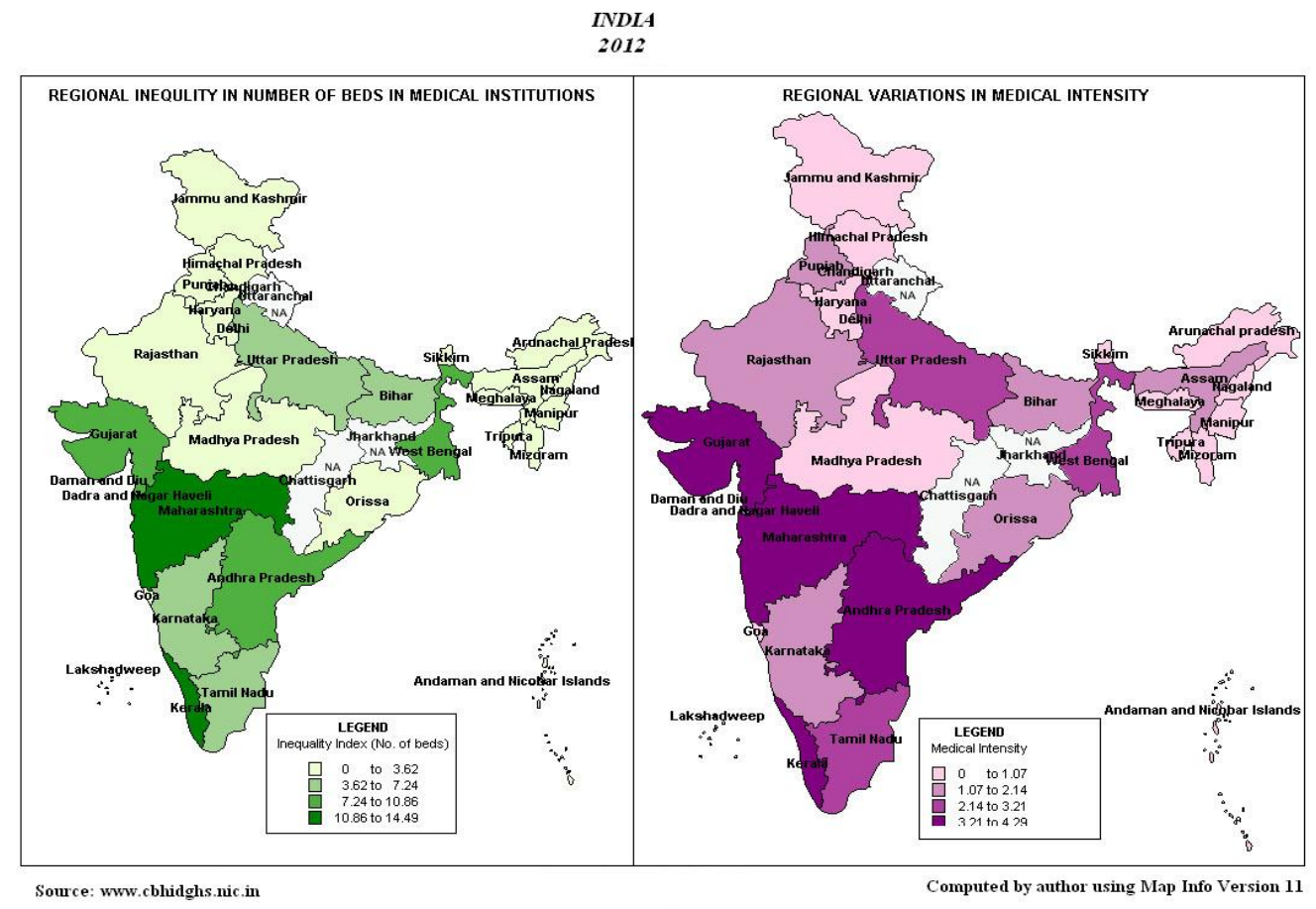

Figure 6

Similarly, the Inequality Index (II) has been plotted in Fig.7, which is an eye-opener with respect to distribution of the number of beds. Out of the 29 Indian states only two states, i.e. Maharashtra and Kerala have an Inequality Index of 14.49 and 14.33 respectively and, thus, reveal the least inequalities, in terms of bed strength. This indicates that these states situated along the western coast of India are endowed with substantial beds to serve its population. The bed-population ratio of Maharashtra is 1: 920 and that of Kerala is 1: 325.These figures are much better than the national average of 1:1503 (www.cbhidghs.nic.in).

Ironically, the ratio in the largest Indian state of Rajasthan is 1:3175, and that of the centrally located state of Madhya Pradesh is 1:5582.This is reflected in the computed values of II, which are 2.55 and 1.58 respectively.

Similar to the variations were found in the medical intensity of West Bengal.Out of the 19 districts of the state, only Kolkata demonstrates 15 a high medical intensity of 3.6. It is significant to note that the Northern districts of Darjeeling, Cooch Bihar, Uttar and Dakshin Dinajpur and Malda have a medical intensity ranging between 1.3 to 1.9 , which reflects fewer hospitals and lesser number of beds. On the other hand, the districts of Murshidabad, Nadia, Barddhaman and South 24 Parganas showed a medical intensity ranging between 2.5 to 3.1 .

Fig.7 illustrates the regional inequality in the number of beds in medical institutions. The districts of Calcutta and Barddhaman stand out having an inequality index of 25.31 and 9.52 respectively. These figures reveal that the population served per bed is lower compared to the districts like Dakshin Dinajpur and Malda having a low inequality index of 1.13 and 1.77 respectively. 


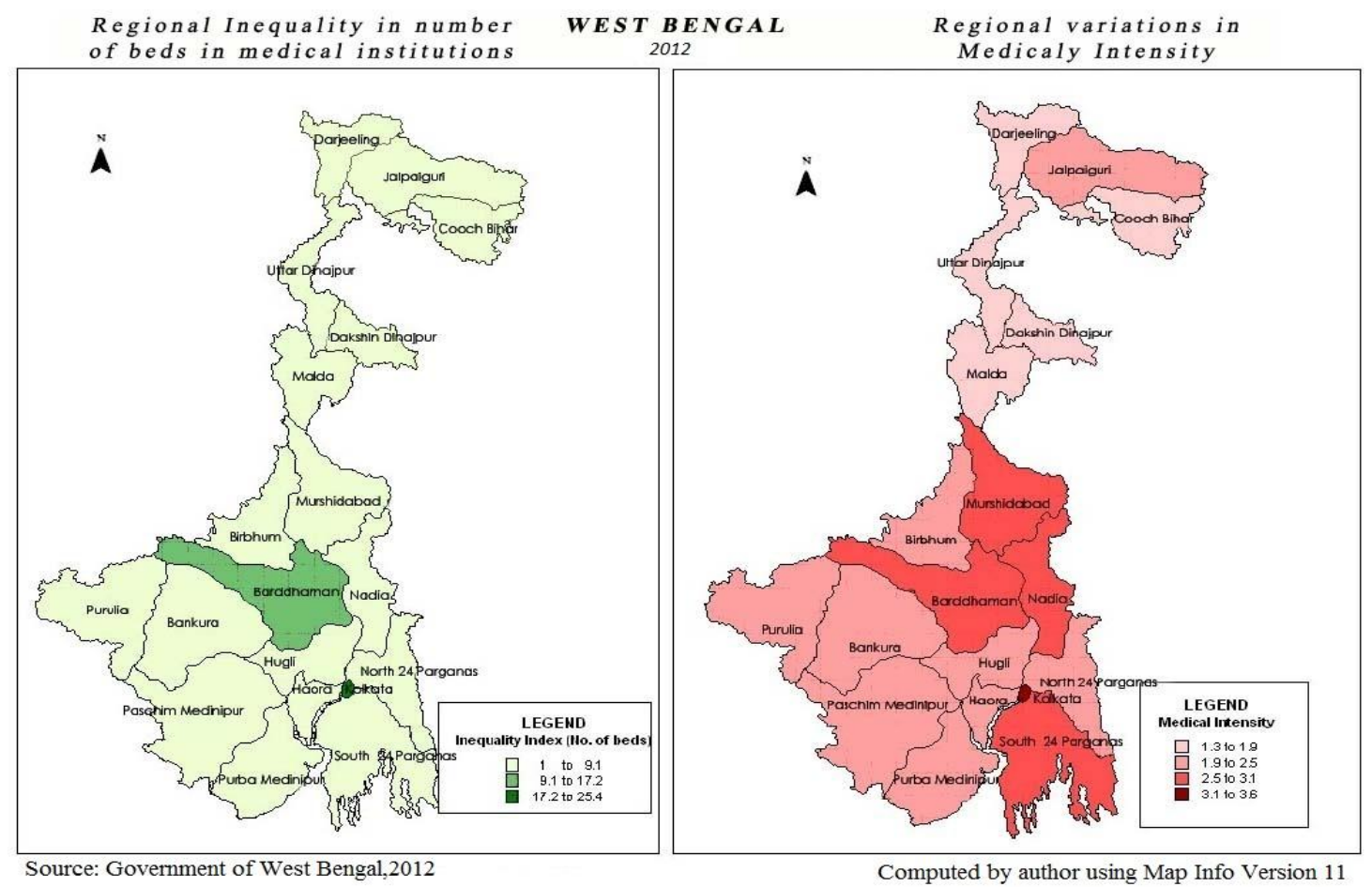

Figure 7

\section{Health Tourism - Destination India}

South Asia is endowed with scenic beauty which has attracted tourists from far and wide. Within the purview of tourism, a comparatively new entrant has been health tourism which has encouraged resource and development of the medical sector. It has broken down all the political and geographical barriers and has accelerated the qualitative advancements in the medical field.

Health and medical tourism is perceived as one of the fastest growing segments in marketing 'Destination India' today. While this area has so far been relatively unexplored, we now find that not only the Ministry of Tourism, Government of India, but also the various state tourism boards and even the private sector consisting of travel agents, tour operators, and hotel companies are all eying health and medical tourism as a segment with tremendous potential for future growth.

Kerala, has pioneered health and medical tourism in India. They have made a concerted effort to promote health tourism in a big way, which has resulted in a substantial increase of visitor arrivals into the state. Kerala and Ayurveda have virtually become synonymous with each other. However, though Kerala has strongly focussed on Ayurveda and its wide array of treatments and medications, good facilities are also available in the other traditional forms of medicine as well as in modern medical treatment.

Mumbai as a gateway to India offers tremendous potential to develop medical tourism. The latest addition is the Asian Heart Institute at Bandra-Kurla Complex, which offers state-of-the art facilities for all types of heart complications and even offers preventive cardiological treatment to avoid heart ailments and also to keep under control a host of heart problems. This institute which is in collaboration with the Cleveland Institute, USA, offers 'five-star' services at reasonable prices.

\section{Conclusion}

Most South Asian countries have failed to maintain balance between economic and social development policies during globalization. An equitable globalization process requires the integration of the financial, trade and investment policies with those of social development. The social services expenditures in the postglobalization period remained stagnant at the prevailing pre-reform levels, reducing the coverage and effectiveness of service delivery. The steps to achieve MDGs should emphasize on identifying the social priority areas, encourage institutional capacity building, sustainable financing and stress on community ownership. It is evident from the comparison of South Asian countries that India lags behind in the ladder of human development. The question therefore is does India need 'more malls' or 'more hospitals'? 
Inclusive growth would lead to human development. South Asian countries need to make sustained efforts in four areas: accelerate human development, especially education; reduce poverty; improve economic management; and enhance regional and global integration.

\section{References}

[1] UNDP, Human Development Reports, 1991, 2000 - 2014

[2] Ranis, G.,et al.,2005.Economic Growth and Human Development, Oxford University Press, New Delhi, pp.62,65,74

[3] The World Bank, 2000.India: Reducing Poverty, Accelerating Development, Oxford University Press, New Delhi

[4] UNICEF, 2013. Levels and Trends in Child Mortality, New York, USA

[5] Deolalikar, A.B.,2005.Attaining the Millennium Development Goals in India, The World Bank, Oxford University Press, Delhi

[6] Council for Social Development, 2006.INDIA: Social Development Report, Oxford University Press, New Delhi

[7] Sample Registration Scheme Bulletins, 2013\& 2005, Ministry of Home Affairs, Government of India.

[8] Government of West Bengal, 2012: Directory of Medical Institutions, West Bengal, 2012, Department of Health and Family Welfare, Government of West Bengal, Kolkata 